\title{
Was the media campaign that supported Australia's new pictorial cigarette warning labels and plain packaging policy associated with more attention to and talking about warning labels?
}

Citation for published version (APA):

Nagelhout, G. E., Osman, A., Yong, H. H., Huang, L. L., Borland, R., \& Thrasher, J. F. (2015). Was the media campaign that supported Australia's new pictorial cigarette warning labels and plain packaging policy associated with more attention to and talking about warning labels? Addictive Behaviors, 49, 64-67. https://doi.org/10.1016/j.addbeh.2015.05.015

\section{Document status and date: \\ Published: 01/10/2015}

DOI:

10.1016/j.addbeh.2015.05.015

Document Version:

Publisher's PDF, also known as Version of record

\section{Document license:}

Taverne

\section{Please check the document version of this publication:}

- A submitted manuscript is the version of the article upon submission and before peer-review. There can be important differences between the submitted version and the official published version of record. People interested in the research are advised to contact the author for the final version of the publication, or visit the DOI to the publisher's website.

- The final author version and the galley proof are versions of the publication after peer review.

- The final published version features the final layout of the paper including the volume, issue and page numbers.

Link to publication

\footnotetext{
General rights rights.

- You may freely distribute the URL identifying the publication in the public portal. please follow below link for the End User Agreement:

www.umlib.nl/taverne-license

Take down policy

If you believe that this document breaches copyright please contact us at:

repository@maastrichtuniversity.nl

providing details and we will investigate your claim.
}

Copyright and moral rights for the publications made accessible in the public portal are retained by the authors and/or other copyright owners and it is a condition of accessing publications that users recognise and abide by the legal requirements associated with these

- Users may download and print one copy of any publication from the public portal for the purpose of private study or research.

- You may not further distribute the material or use it for any profit-making activity or commercial gain

If the publication is distributed under the terms of Article 25fa of the Dutch Copyright Act, indicated by the "Taverne" license above, 


\title{
Was the media campaign that supported Australia's new pictorial cigarette warning labels and plain packaging policy associated with more attention to and talking about warning labels?
}

\author{
Gera E. Nagelhout a,b,*, Amira Osman ${ }^{\mathrm{c}}$, Hua-Hie Yong ${ }^{\mathrm{d}}$, Li-Ling Huang ${ }^{\mathrm{e}}$, Ron Borland ${ }^{\mathrm{d}}$, James F. Thrasher ${ }^{\mathrm{c}, \mathrm{f}}$ \\ a Department of Health Promotion, Maastricht University (CAPHRI), Maastricht, The Netherlands \\ ${ }^{\mathrm{b}}$ Dutch Alliance for a Smokefree Society, The Hague, The Netherlands \\ c Department of Health Promotion, Education and Behaviour, University of SC, Columbia, SC, USA \\ ' Nigel Gray Fellowship Group, Cancer Council Victoria, St Kilda, Victoria, Australia \\ e Center for Regulatory Research on Tobacco Communication, Lineberger Comprehensive Cancer Centre, University of NC, Chapel Hill, USA \\ ${ }^{\mathrm{f}}$ Department of Tobacco Research, Center for Population Health Research, National Institute of Public Health, Cuernavaca, Mexico
}

\section{H I G H L I G H T S}

- Australia implemented a plain packaging policy for cigarette packages in 2012.

- Pictorial health warning labels (HWLs) on cigarette packages were also updated.

- A national mass media campaign was aired that complemented the labeling policies.

- Recall of the campaign was associated with more attention to and talking about HWLs.

- Adjusting for campaign recall, there was still an increase in attention and talking.

\section{A R T I C L E I N F O}

\section{Available online 5 June 2015}

\section{Keywords:}

Australia

Media campaign

Public policy

Smoking

Warning labels

\begin{abstract}
A B S T R A C T
Background: Population-level interventions can possibly enhance each other's effects when they are implemented simultaneously. When the plain packaging policy was implemented in Australia, pictorial health warning labels (HWLs) on cigarette packages were also updated and a national mass media campaign was aired. This study examined whether smokers who recalled the media campaign reported more attention to and talking about HWLs.

Methods: Longitudinal survey data was obtained among Australian adult smokers, aged 18 years and older, from an online consumer panel. One survey wave was conducted before (September 2012) and two waves were conducted after (January 2013 and May 2013) the interventions. The sample was replenished to maintain a sample size of 1000 participants at each wave. Generalized Estimating Equations analyses were performed.

Results: Compared to wave 1, attention to HWLs increased at wave $2(b=0.32, \mathrm{SE}=0.06, p<0.001)$, but not at wave 3 ( $b=0.10, \mathrm{SE}=0.08, p=0.198$ ). Talking about HWLs increased over time ( $\mathrm{IRR}=1.82,95 \% \mathrm{CI}=1.58$ 2.09 and $\mathrm{IRR}=1.25,95 \% \mathrm{Cl}=1.05-1.47$, at wave 2 and wave 3 respectively). Campaign recall was significantly associated with more attention to HWLs $(b=0.29, \mathrm{SE}=0.05, p<0.001)$ and with more talking about HWLs $($ IRR $=1.17,95 \% \mathrm{CI}=1.06-1.29)$ with similar effects across waves 2 and 3 .

Conclusions: Recall of the campaign was associated with more attention to and talking about HWLs. When adjusting for campaign recall, there was still an increasing trend in attention and talking. This suggests that the media campaign and the new packaging and labeling policies had independent and positive effects on attention to and talking about HWLs.
\end{abstract}

(c) 2015 Elsevier Ltd. All rights reserved.
* Corresponding author at: Maastricht University, Department of Health Promotion, PO Box 616, 6200 MD Maastricht, The Netherlands. Tel.: +31 612947031.

E-mail address: Gera.Nagelhout@MaastrichtUniversity.nl (G.E. Nagelhout).

\section{Introduction}

To increase the effectiveness of population-level interventions, it is sometimes argued that they should be implemented simultaneously to create synergistic effects (Devlin et al., 2005; O'Hegarty et al., 2007; Strahan et al., 2002). At the end of 2012, Australia implemented a policy 
that obliged all tobacco products to be sold in standardized ('plain') packaging (Commonwealth of Australia, 2011). Simultaneously, Australia implemented new pictorial cigarette health warning labels (HWLs) and aired a media campaign about the health effects of smoking and the benefits of quitting (Wakefield et al., 2013). Attention to and talking about policies are both factors that are very proximal to policies and campaigns and are known to be influenced first before more general determinants of smoking cessation are influenced (Fong et al., 2006; Van den Putte et al., 2011; Yong et al., 2014). Therefore, this study examines whether smokers who recalled the media campaign reported more attention to and talking about HWLs.

Little is known about the synergistic or complementary effects of media campaigns with tobacco control policies (Hammond et al., 2013). Findings from a few studies are suggestive of such effects (Brennan et al., 2011; Thrasher et al., 2013; Wakefield et al., 2013; White et al., 2008), but most of these studies are cross-sectional and can thus not determine causal relationships. Only one sub-study in the paper by Brennan et al. (2011) was longitudinal, but it only examined respondents after the implementation of a warning label policy and the follow-up was only a few days after the baseline survey. Wakefield and colleagues (2013) used cross-sectional data to examine the Australian packaging and labeling policies and the media campaign that are also examined in the current study. It was found that smokers who were smoking from plain packs with new HWLs during the phase-in period of the policy had a higher rate of recall of the media campaign than those who were smoking from branded packs with the smaller HWLs (Wakefield et al., 2013), suggesting that the policies and the media campaign enhanced each other's effects. In order to understand the possible synergistic or complementary effects of media campaigns with tobacco control policies better, it is important to smokers for a longer time period using longitudinal data and to also include a pre-law baseline survey.

The Australian plain packaging policy stipulates that no branding design elements are allowed on cigarette packages, that all packages are colored drab brown, and that brand and variant names appear in standard font and size. The first standardized cigarette packages started to appear in early October 2012, and from December 1st 2012 all tobacco products sold in Australia were required to be in this kind of standardized packaging. The HWLs were updated in the same period with a new set of 14 pictorial warnings where the size of these warnings was increased from $30 \%$ to $75 \%$ of the front of the pack while that of the back of the pack remained at $90 \%$. The labeling change was accompanied by a national mass media campaign which was aired on television between November 4, 2012 and January 26, 2013 and between April 14 and June 29, 2013. The campaign covered several health effects of smoking that were included on the HWLs, including blindness, lung cancer, and pregnancy-related harm.

Our research question was: Was recall of the media campaign that supported Australia's new pictorial HWLs and the implementation of plain packaging policy associated with more attention to and talking about HWLs among smokers?

\section{Methods}

\subsection{Sample}

Longitudinal data were obtained from three survey waves among Australian adult smokers, aged 18 years and older, who were recruited from an online consumer panel provided by Global Market Insights (GMI: http://www.gmi-mr.com). Panel participants were selected to be broadly representative of key consumer segments in Australia. Eligible participants were smokers who smoked at least 100 cigarettes in their lifetime, and smoked at least once in the previous month. One survey wave was conducted before (wave 1, 10 September 2012-30 September 2012) and two survey waves (wave 2, 15 January 2013-7 February 2013, and wave 3, 15 May 2013-9 June 2013) were conducted after the campaign, the new HWLs, and the plain packaging policy were implemented.

At each wave a 1000 Australian smokers participated in the study. Respondents were followed up over time. Follow up rate was $65 \%$ at wave 2 and $68 \%$ at wave 3 . Respondents lost to follow-up were replenished to maintain a sample size of 1000 respondents at each wave. The analytic sample for the current study included smokers ( $n=2666$ observations, $n=1579$ participants) who had no missing data on any of the variables.

\subsection{Measures}

Attention to warning labels was measured with two items: 'In the last month, how often, if at all, have you noticed health warnings on cigarette packages?', and 'In the last month, how often, if at all, have you read or looked closely at the warning labels on cigarette packages?', with response options on a 5-point scale ('never', 'rarely', 'sometimes', 'often', and 'very often') (Thrasher et al., 2013; Yong et al., 2014). Scores for the two items were averaged to form a continuous variable (range 1-5).

Talking about warning labels was measured with three items: 'In the last month, how often have you talked to others about the warning labels on cigarette packs?', 'In the last month, how often have your family members spoken with you about the warning labels on cigarette packs?', and 'In the last month, how often have other people besides your family spoken with you about the warning labels on cigarette packs?' Response options were 'not at all', 'once', 'a few times', 'often', and 'very often'. These three items were dichotomized (not at all versus the rest) and then summed into a count variable (range 0-3) with higher numbers indicating more talking about HWLs.

Campaign recall was only assessed at waves 2 and wave 3 as there was no campaign at wave 1 using a single question: 'In the last month, have you seen any anti-smoking ads on television, which talked about the dangers of smoking?', with dichotomized responses ( 1 = 'yes', $0=$ 'no', 'don't know' or not asked).

Control variables were age, gender, education, income, daily versus non-daily smoker, smoking intensity, quit intention, previous quit attempts, and time in sample (i.e. the number of survey waves the respondent participated in). Education was categorized into low (high school or less), moderate (college or some university), and high (completed university or higher). Income was categorized into low (less than $\$ 30,000)$, moderate $(\$ 30,000-\$ 59,999)$, and high ( $\$ 60,000$ or more). The Heaviness of Smoking Index (HSI) was used to assess smoking intensity and combines information on the number of cigarettes smoked per day and time before smoking the first cigarette of the day (Heatherton et al., 1989).

\subsection{Analyses}

Analyses were performed using Stata version 13. Chi-square tests were used to assess differences in sample characteristics across waves and differences in the outcome measures (i.e., attention and talking about HWLs) between respondents who recalled the campaign and those who did not recall the campaign.

Generalized Estimating Equations (GEE) analyses were performed to examine whether attention to and talking about HWLs changed over time and whether campaign recall was associated with attention and talking. Linear GEE models were estimated when examining attention to HWLs as the outcome and Poisson GEE models were estimated when examining talking about HWLs as the outcome. The exchangeable correlation structure was used with robust variance estimators. The repeated measures variable was survey wave. All GEE models adjusted for age, gender, education, income, daily versus non-daily smoker, HSI, quit intention, previous quit attempts, and time in sample.

In sensitivity analyses, we added a weight factor based on gender, age, and education and propensity scores based on time in sample and 
Table 1

Sample characteristics by survey wave ( $n=2666$ observations).

\begin{tabular}{|c|c|c|c|}
\hline & Wave 1 & Wave 2 & Wave 3 \\
\hline & $(n=901)$ & $(n=887)$ & $(n=878)$ \\
\hline Age (mean, SD) & $42.2(13.0)$ & $43.2(12.3)$ & $43.0(12.5)$ \\
\hline \multicolumn{4}{|l|}{ Gender } \\
\hline Male & $42.5 \%$ & $41.5 \%$ & $43.8 \%$ \\
\hline Female & $57.5 \%$ & $58.5 \%$ & $56.2 \%$ \\
\hline \multicolumn{4}{|l|}{ Education $^{\mathrm{a}}$} \\
\hline High school or less & $33.30 \%$ & $37.9 \%$ & $36.4 \%$ \\
\hline College or some university & $410.3 \%$ & $42.7 \%$ & $44.2 \%$ \\
\hline Completed university or higher & $25.4 \%$ & $19.4 \%$ & $19.4 \%$ \\
\hline \multicolumn{4}{|l|}{ Income } \\
\hline$\$ 29,999$ or less & $23.0 \%$ & $24.1 \%$ & $23.6 \%$ \\
\hline$\$ 30,000-\$ 59,999$ & $27.7 \%$ & $25.0 \%$ & $28.5 \%$ \\
\hline$\$ 60,000$ or more & $49.3 \%$ & $50.9 \%$ & $47.9 \%$ \\
\hline
\end{tabular}

${ }^{\text {a }} p<0.05$, omnibus $\chi^{2}$ test for differences in sample characteristics across waves.

all potential variables that may be associated with time in sample (e.g. employment status, marital status, number of online surveys completed in the last four months, number of online surveys on smoking in the last month, and overall health status) to the analyses. The pattern of results was similar to the results without correction for weights and propensity scores and therefore the uncorrected results are reported.

\section{Results}

Sample characteristics by survey wave are shown in Table 1 . Average age was 42 years (range 18-71). Approximately $42 \%$ of the sample were male and about one third of participants had high school education or less. Across all waves about $23 \%$ of the sample reported an income of less than $\$ 30,000$. Except for education, no statistically significant differences were observed in the sample characteristics across waves.
Statistically significant differences in the outcome measures were observed across waves. Generally, a significant higher percentage of participants reported noticing, reading, and talking about HWLs at wave 2 and wave 3 compared to wave 1 (Table 2). Also, statistically significant differences in the outcomes distribution were observed between those who recalled the campaign and those who did not. At wave 2 and at wave 3, in general, a higher percentage of participants among those who recalled the campaign reported noticing, reading, and talking about HWLs compared to those who did not recall the campaign.

GEE models showed that, compared to wave 1, attention to HWLs increased at wave $2(b=0.32, \mathrm{SE}=0.06, p<0.001)$, but did not at wave 3 $(b=0.10, \mathrm{SE}=0.08, p=0.198)$. Campaign recall was significantly associated with more attention to HWLS $(b=0.29, \mathrm{SE}=0.05, p<0.001)$. Talking about HWLs increased at wave 2 (IRR $=1.82,95 \% \mathrm{CI}=1.58-$ $2.09, p<0.001$ ) and wave 3 (IRR $=1.25,95 \% \mathrm{CI}=1.05-1.47$, $p<0.01$ ) compared to wave 1 . Campaign recall was also significantly associated with more talking about HWLs (IRR $=1.17,95 \% \mathrm{CI}=1.06-$ $1.29, p<0.01)$. There were no significant interactions between campaign recall and survey wave.

\section{Discussion}

When the plain packaging policy was implemented in Australia, the pictorial cigarette warning labels were also updated and a national mass media campaign was aired. The media campaign featured several health effects of smoking that were also included on the HWLs and thus they may have enhanced the effectiveness of the warning labels. The results of our study indeed show that recall of the media campaign among Australian smokers was associated with more attention to and talking about HWLs. When adjusting for campaign recall, there was still an increasing trend in attention to and talking about HWLs between before and after the implementation of the plain packaging policy and the new pictorial HWLs. This suggests that not only the campaign had a positive influence on attention and talking, but that the new packaging and

Table 2

Attention to and talking about health warning labels (HWLs) by survey wave and campaign recall ( $n=2666$ observations).

\begin{tabular}{|c|c|c|c|c|c|c|c|}
\hline & \multirow{4}{*}{$\begin{array}{l}\text { Wave } 1 \\
\frac{\text { Total }}{(n=901)}\end{array}$} & \multicolumn{3}{|l|}{ Wave 2} & \multicolumn{3}{|l|}{ Wave 3} \\
\hline & & \multicolumn{2}{|c|}{ Campaign recall } & \multirow{3}{*}{$\begin{array}{l}\text { Total } \\
\overline{(n=887)}\end{array}$} & \multicolumn{2}{|c|}{ Campaign recall } & \multirow{3}{*}{$\begin{array}{l}\text { Total } \\
(n=878)\end{array}$} \\
\hline & & \multirow{2}{*}{$\frac{\text { No }}{(n=287)}$} & \multirow{2}{*}{$\frac{\text { Yes }}{(n=600)}$} & & \multirow{2}{*}{$\frac{\text { No }}{(n=281)}$} & \multirow{2}{*}{$\frac{\text { Yes }}{(n=597)}$} & \\
\hline & & & & & & & \\
\hline \multicolumn{8}{|c|}{ How often noticed HWLs? ${ }^{c}$} \\
\hline Never/sometimes & $72.1 \%$ & $71.4 \%$ & $51.2 \% * * *$ & $57.7 \%$ & $80.4 \%$ & $56.6 \%^{* * *}$ & $64.2 \%$ \\
\hline Often/very often & $27.9 \%$ & $28.6 \%$ & $48.8 \%$ & $42.3 \%$ & $19.6 \%$ & $43.4 \%$ & $35.8 \%$ \\
\hline \multicolumn{8}{|l|}{ How often read HWLs? ${ }^{c}$} \\
\hline Never/sometimes & $90.1 \%$ & $88.1 \%$ & $80.8 \% * *$ & $83.2 \%$ & $90.7 \%$ & $84.2 \% * *$ & $86.3 \%$ \\
\hline Often/very often & $9.9 \%$ & $11.9 \%$ & $19.2 \%$ & $16.8 \%$ & $9.3 \%$ & $15.8 \%$ & $13.7 \%$ \\
\hline Attention (mean, SD) ${ }^{\mathrm{c}}$ & $2.48(1.02)$ & $2.58(1.09)$ & $3.02(1.06)^{* * *}$ & $2.88(1.08)$ & $2.27(1.02)$ & $2.85(1.02)^{* * *}$ & $2.66(1.05)$ \\
\hline \multicolumn{8}{|c|}{ Talked to others about HWLs? ${ }^{c}$} \\
\hline Not at all & $72.5 \%$ & $54.7 \%$ & $40.5 \% * * *$ & $45.0 \%$ & $72.3 \%$ & $57.0 \% * * *$ & $61.8 \%$ \\
\hline Once/Very often & $27.5 \%$ & $45.3 \%$ & $59.5 \%$ & $55.0 \%$ & $27.7 \%$ & $43.0 \%$ & $38.2 \%$ \\
\hline \multicolumn{8}{|c|}{ Family spoke with you about HWLs? ${ }^{c}$} \\
\hline Not at all & $75.6 \%$ & $69.5 \%$ & $61.2 \% *$ & $63.8 \%$ & $76.3 \%$ & $70.6 \%$ & $72.4 \%$ \\
\hline Once/Very often & $24.4 \%$ & $30.5 \%$ & $38.8 \%$ & $36.2 \%$ & $23.7 \%$ & $29.4 \%$ & $27.6 \%$ \\
\hline \multicolumn{8}{|c|}{ Non-family spoke with you about HWLs? ${ }^{c}$} \\
\hline Not at all & $76.8 \%$ & $66.8 \%$ & $56.2 \% * *$ & $59.7 \%$ & $75.3 \%$ & $70.5 \%$ & $72.0 \%$ \\
\hline Once/Very often & $23.2 \%$ & $33.2 \%$ & $43.8 \%$ & $40.3 \%$ & $24.7 \%$ & $29.5 \%$ & $28.0 \%$ \\
\hline \multicolumn{8}{|l|}{ Talk about HWLs index ${ }^{c}$} \\
\hline 0 & $65.0 \%$ & $50.2 \%$ & $33.7 \% * * *$ & $39.0 \%$ & $65.5 \%$ & $49.6 \% * * *$ & $54.7 \%$ \\
\hline 1 & $10.6 \%$ & $12.6 \%$ & $18.8 \%$ & $16.8 \%$ & $10.0 \%$ & $17.8 \%$ & $15.3 \%$ \\
\hline 2 & $9.2 \%$ & $16.0 \%$ & $19.8 \%$ & $18.6 \%$ & $8.9 \%$ & $14.4 \%$ & $12.6 \%$ \\
\hline 3 & $15.2 \%$ & $21.2 \%$ & $27.7 \%$ & $25.6 \%$ & $15.6 \%$ & $18.2 \%$ & $17.4 \%$ \\
\hline
\end{tabular}

${ }^{\mathrm{a}} p<0.05,{ }^{\mathrm{b}} p<0.01,{ }^{\mathrm{c}} p<0.001$, omnibus $F$ test or $\chi^{2}$ test for differences in study outcomes across all three waves.

${ }^{*} p<0.05,{ }^{* *} p<0.01,{ }^{* * *} p<0.001$, omnibus $F$ test or $\chi^{2}$ test for within wave differences in study outcomes between those who recall and those who do not recall the campaign. 
labeling policies had independent effects on these outcomes as well. It should be noted, however, that attention to and talking about HWLS was not something that a lot of smokers reported. With the exception of the first survey wave after the implementation of the policies, the majority of smokers reported not to have noticed, read or looked closely, or talked about the HWLs at all in the last month at the other survey waves. Nevertheless, our study is the first study with pre-post intervention design that examined complementary relationships between campaigns and packaging and labeling policies with longitudinal data, and the findings are in line with previous cross-sectional studies (Thrasher et al., 2013; Wakefield et al., 2013; White et al., 2008) and one longitudinal study that only surveyed respondents after the implementation of a warning label policy (Brennan et al., 2011). Future research is needed to disentangle effects of plain packaging from effects of HWLs.

There are some limitations to this study that are important to mention. First, the sample of smokers used for this study was part of an online consumer panel that may not be totally representative of the population of smokers. Although panel participants were selected to be broadly representative of key consumer segments in Australia, the precise sampling frame is unknown. Second, self-reported recall of the campaign and attention to HWLs were used as proxies for campaign exposure and HWL exposure. Therefore, our estimates may be biased by memory recall and social desirability and may not totally reflect the actual exposure to the campaign and/or the HWLs. Also, the campaign recall variable asked about any anti-smoking ads on television which talk about the dangers of smoking. Although the national mass media campaign that accompanied the labeling change was the only one aired during the survey time, this is a very generic measure that does not explicitly refer to this specific campaign. Future research should ask about recall of specific campaigns and should also measure general recall of campaigns when no campaign is aired to adjust for any selfreport bias. Finally, although we used longitudinal data, GEE results may have reflected cross-sectional relations, which make it difficult to draw causal conclusions from this study.

In the current study we examined associations of campaign recall with attention to HWLs and talking about them. We can, therefore, draw no conclusions about effects on knowledge of the health effects of smoking and on smoking cessation intention and behavior. Our results do suggest that running a media campaign about the health effects of smoking and the benefits of quitting that is complementary to warning label contents may help to enhance smokers' attention to warning labels and stimulate talking about these labels, thus increasing their reach and possibly their effectiveness.

\section{Role of funding sources}

This work was supported by the U.S. National Cancer Institute, grant number (R01 CA167067). The funder had no involvement in the design of the study, the collection, analysis and interpretation of the data, the writing of the paper, or the decision to submit the paper for publication.

\section{Contributors}

GEN drafted the manuscript. AO conducted the statistical analysis. JFT supervised the drafting of the manuscript and the statistical analyses and is the guarantor of the paper. All authors contributed to the data interpretation and to the writing of the manuscript. All authors revised the manuscript critically for important intellectual content and read and approved the final manuscript.

\section{Conflict of interest}

No conflict declared.

\section{References}

Brennan, E., Durkin, S.J., Cotter, T., Harper, T., \& Wakefield, M.A. (2011). Mass media campaigns designed to support new pictorial health warnings on cigarette packets: Evidence of a complementary relationship. Tobacco Control, 20, 412-418.

Commonwealth of Australia (2011). Tobacco Plain Packaging Act 2011 (no. 148, 2011). Available at: http://www.austlii.edu.au/au/legis/cth/num_act/tppa2011180/ (accessed 1 August, 2014)

Devlin, E., Anderson, S., Hastings, G., \& MacFayden, L. (2005). Targeting smokers via tobacco product labelling: Opportunities and challenges for Pan European health promotion. Health Promotion International, 20, 41-49.

Fong, G.T., Cummings, K.M., Borland, R., Hastings, G., Hyland, A., Giovino, G.A., et al. (2006). The conceptual framework of the International Tobacco Control (ITC) Policy Evaluation Project. Tobacco Control, 15(Suppl. 3), 3-11.

Hammond, D., Wakefield, M., Durkin, S., \& Brennan, E. (2013). Tobacco packaging and mass media campaigns: Research needs for articles 11 and 12 of the WHO Framework Convention on Tobacco Control. Nicotine E Tobacco Research, 15, 817-831.

Heatherton, T.F., Kozlowski, L.T., Frecker, R.C., Rickert, W., \& Robinson, J. (1989). Measuring the heaviness of smoking: Using self-reported time to the first cigarette of the day and number of cigarette smoked per day. British Journal of Addiction, 84, 791-800.

O'Hegarty, M., Pederson, L.L., Yenokyan, G., Nelson, D., \& Wortley, P. (2007). Young adults' perceptions of cigarette warning labels in the United States and Canada. Preventing Chronic Disease, 4, A27.

Strahan, E.J., White, K., Fong, G.T., Fabrigar, L.R., Zanna, M.P., \& Cameron, R. (2002). Enhancing the effectiveness of tobacco package warning labels: A social psychological perspective. Tobacco Control, 11, 183-190.

Thrasher, J.F., Murukutla, N., Péréz-Hernández, R., Alday, J., Arillo-Santillán, E., Cedillo, C., et al. (2013). Linking mass media campaigns to pictorial warning labels on cigarette packages: A cross-sectional study to evaluated effects among Mexican smokers. Tobacco Control, 22(e1), e57-e65.

Van den Putte, B., Yzer, M., Southwell, B.G., De Bruijn, G. -J., \& Willemsen, M.C. (2011). Interpersonal communication as an indirect pathway for the effect of antismoking media content on smoking cessation. Journal of Health Communication, 16, 470-485.

Wakefield, M.A., Hayes, L., Durkin, S., \& Borland, R. (2013). Introduction effects of the Australian plain packaging policy on adult smokers: A cross-sectional study. BMJ Open, 3, e003175.

White, V., Webster, B., \& Wakefield, M. (2008). Do graphic health warning labels have an impact on adolescents' smoking-related beliefs and behaviours? Addiction, 103, 1562-1571.

Yong, H. -H., Borland, R., Thrasher, J.F., Thompson, M.E., Nagelhout, G.E., Fong, G.T., et al. (2014). Mediational pathways of the impact of cigarette warning labels on quit attempts. Health Psychology, 33, 1410-1420. 